\title{
ASPECTS OF COMPLEXITY OF METAL-FIBROUS MICROSTRUCTURE FOR THE CONSTRUCTION OF HIGH-PERFORMANCE HEAT EXCHANGERS: ESTIMATION OF ADHESIVE STRENGTH
}

\author{
Rafał CHATYS (1D * \\ Faculty of Mechatronics and Mechanical Engineering, Kielce University of Technology, Kielce, Poland
}

Received 9 July 2019; accepted 15 January 2020

\begin{abstract}
The paper deals with aspects of the complexity of mechanical properties of porous structures made from copper fibers and fibers reinforced with copper meshes to assess the adhesive strength of the fibrous structure and the cohesion between the components of the tested elements used for the construction of heat exchangers. All of the tested samples were characterized by macroscopic open porosity. The internal structure of the obtained connections was analyzed by metallographic techniques. Statistical relations of the connections made between the layers have been provided. The side effects of the production technology related to the "hydrogen disease" of copper have been discussed.
\end{abstract}

Keywords: adhesive strength, copper, technology, metal - fibrous structures.

\section{Introduction}

Components with fibrous structures are used to transfer large heat fluxes in various applications (Chatys \& Koruba, 2005; Gapiński \& Stefański, 2014), especially in the construction of heat exchangers (Verdy et al., 1998; Bar-Cohen \& Simon, 1986; Chatys, \& Wójcik, 2008). Such phase - change heat exchangers can be part of refrigeration and air - conditioning units in planes and their thermal performance indirectly affects the overall performance of the whole system (including fuel consumption and thermal comfort conditions related to proper temperature onboard). Heat exchangers with fibrous structures can be more efficient than the traditional ones (Orman, 2020), consequently their use in aviation systems (as part of refrigeration and air - conditioning units) can be very effective. Those systems undergo vibration during normal operation, thus knowledge on their strength characteristics is important. Quite well-formulated are the requirements that should be met by porous structures due to heat exchange parameters (such as reducing adverse thermal phenomena, in particular the elimination of film boiling and supporting the capillary supply of the layer (Fang et al., 2016; Orman, 2016), which are very complex and interrelated (Cheng et al., 2018).

The change in the state of aggregation in the process of heat exchange (during the flow through channels or minichannels) of different geometries (Bohdal, 2017; Kuczyński,
2019) in the era of miniaturization, results in slight heat loss with a small temperature difference between the recipient (radiator) and saturated liquid (i.e. possibility of transporting a significant heat stream). And heat exchange during the flow of boiling liquid through microchannels in mathematical problems are solved by reverse heat conduction problems (Song \& Chang, 2015; Piasecka \& Poniewski, 2016) not only by the Treffz method (Reutskiy, 2004) or Picard.

Modeling of phenomena accompanying flows in mini- and micro-channels (in channels with small crosssections), taking into account two-phase flow resistance at condensation and boiling, are considered and analyzed by many teams (Mikielewicz et al., 2016; Laguerre et al., 2008). An even more interesting issue (Kamel \& Lezsovits, 2018) are flow tests (with forced convection of heat transfer inside a vertical tube) of nanofluids $\left(\mathrm{Al}_{2} \mathrm{O}_{3} /\right.$ water or $\mathrm{TiO}_{2} /$ water), whose average Nusselt number (for nanofluids) and Reynolds number is higher than water (especially for $\mathrm{TiO}_{2}$ / water nanofluids.

Unfortunately, the available literature (Kandlikar \& Grande, 2003) is negligible and does not contain important technological (Hussein, 2015) and mechanical details regarding such structures with copper (Chatys \& Wójcik, 2008), brass, aluminum, steel fibers or their foams (Li \& Leong, 2011; Zhao et al., 2009; Klett, 2000; Leong, \& Jin, 2008). The variety of applied micro-surfaces (Poniewski, 2001; Thome, 1990) is very large (as evidenced by the

${ }^{\star}$ Corresponding author. E-mail: chatys@tu.kielce.pl 
patented names of commercial products), but there is no systematic study of the impact of structure parameters on the heat transfer coefficient, and a uniform view of the mechanism of this process resulting from the quality of connections between components of the structure, and adhesive strength of the structure (despite the rapid growth of scientific works that have appeared in recent years (Zimon, 1977; Good, 1975; Cheng et al., 2018).

The stimulator of the theoretical explanation of the phenomenon of adhesion, quality and durability of joints in the structure was caused by the needs of industry (especially in the use of glued joints). The creator of the mechanical theory of adhesion dating back to the beginning of our century was Mc Bain, who noticed that the strength of structural components increases as the surface roughness of joined materials increases. The development of this theory with considered by, among others Borroff, Wake, or Sickfeld (Sickfeld, 1983), who stated that improved adhesive strength in the structure between the components of the material resulted from, among others, the sum of intermolecular interactions taking place in a joints or structure. The phenomenon of mutual diffusion (namely, the difference of thermodynamic potentials of molecules as a result of changes in the mutual position of atoms and particles located in the interfacial area) of particles of two different materials (as internal stress in the interfacial zone) brought into direct contact is the basic topic of diffusion theory of adhesion (Voyutskii, 1963).

Adhesive strength is often the basic criterion for the adhesive connection assessment, and determined by different methods, it is different and generally incomparable. It depends on the construction of the joint, but also on the method of decohesion. However, the condition of repeatability of test results performed by any method is a careful and uniform preparation of sintering. The smallest deviations from the adopted rules, both in the course of performing a static tensile test and during testing, can be a source of very large errors. This durability depends to a large extent on the stress distribution in the tested joint, mechanical properties $(\sigma, E)$ and the extent and nature of their deformation. In the case of composite materials, this is often decisive (Vakula \& Pritykin, 1984).

The aim of the research was to obtain a sintered material consisting of a copper fibrous structure with a complex porosity through diffusion joints with the base. The measure of this strength of diffusion joints is better quality of joints, bridges between the fibers forming the porous structure and the base, as a result of high sintering temperature, and increasing the contact surface between the components of the structure.

\section{The choice of material and the course of the study}

For the implementation of the task, copper materials in the form of fibers and mesh have been selected, respectively with a fixed wire diameter of up to $50 \mu \mathrm{m}$ and a thickness of $0.125 \mathrm{~mm}$ (of about $125 \mathrm{mesh} / \mathrm{cm}^{2}$ ). In the research a copper mesh more than twice the diameter of

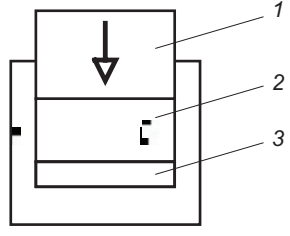

a)

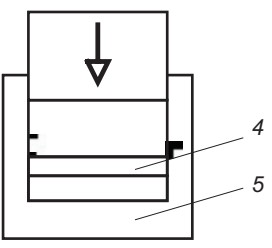

b)
Figure 1. Production of profiles of a) fibrous and b) fibrousmesh structures; 1 - clamping stamp; 2 - copper fibers; 3 - base; 4 - copper mesh; 5 - graphite mould

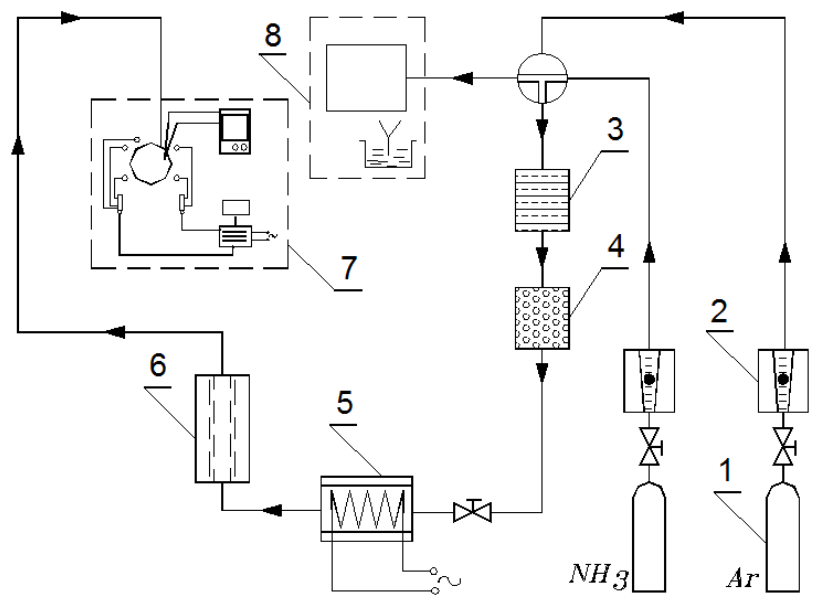

Figure 2. Stand diagram for porous structures bonding: $1-\mathrm{NH}_{3}$ and Ar containers; 2 - rotameter; 3 - filter; 4 - retort; 5 - ammonia dissociation chamber and evaporator; 6 - flame damper; 7 - furnace; 8 - dew-point gauge

fiber material was used, because the small diameter of the copper wire gave a low adhesive strength of the structure (a small contact surface between components), limiting the use of such surfaces in heavily loaded exchangers. The structures were prepared in a specially designed form, in accordance with the recommendations of ISO 2740 for tensile tests. On its surface, $3 \mathrm{~mm}$ wire elements were randomly applied, which were pressed (Figure 1) into the assumed porosity (namely, the given height $h$ ). The technology of sintering fibrous structures was tested in a tube furnace with a reducing atmosphere of controlled composition (Figure 2), the scheme and description of which were included in (Chatys \& Orzechowski, 2004). Prepared matrices with moldings were placed in a sintering zone with a given and controlled temperature, varying in the range of $70-80 \%$ of the melting temperature of copper.

The samples thus prepared were subjected to a static tensile test on the INSTRON 8505 machine in order to test the adhesive strength of the structure with the mesh and between the components in the fibrous structure. As a result of the measurement, the arithmetic mean value of the breaking force of the adhesive joint from at least three measurements was taken. The examination of detachment of a given fibrous structure from copper (Figure $3 a$ ) from the base, reinforced with a copper mesh (Figure 3b) was analyzed in terms of the number and quality of connections in the cross-section of the structure. Diffusion connections were measured randomly in selected i-volumes $\left(\mathrm{V}_{\mathrm{i}}\right)$. 


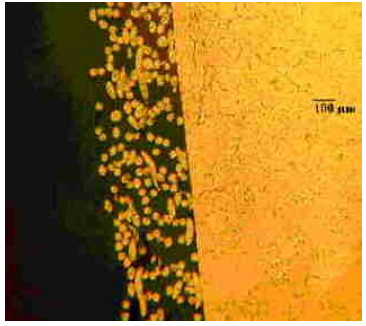

a)

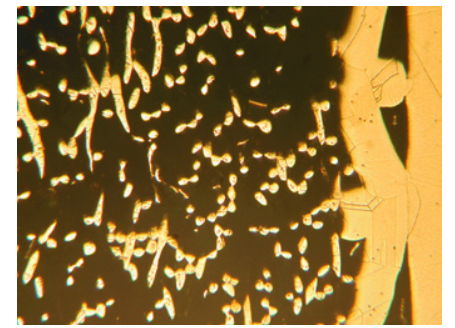

b)
Figure 3. Porous structure with the base: a - fibrous; b - reinforced copper mesh

The analysis of the proper selection of sintering parameters of the structures was carried out with metallographic methods using quantitative metallography due to the occurrence of diffusion bridges and connections formed by melting. The obtained porous structures were cut on a metallographic cutter by the BUEHLER company - the IZOMET LS model with the use of $15 \mathrm{HC}$ composite shields. The samples were then incubated with cold vacuum in an EPO-THIN polyester resin. After grinding, the samples were polished using a BUEHLER preparation set based on a polycrystalline diamond abrasive. The quantitative characterization of the structure of composite layers was determined with the software using an image analyzer to count and analyze individual pixels. The measurement system consisted of a Hitachi KP2M CCD camera processing images and two PCs, one of which was equipped with an AVER TV card, and the other with Media TV Capture for capturing images from the camera and recording them on the disk.

\section{Impact of the quality of diffusion joints on the mechanical properties of the fibrous structure}

Determination of the structure porosity at the level of 6781\% (Orman, 2020) with additional operations (pressing) before and after sintering, resulted in good fiber consolidation and increased contact between fibers' surfaces, with expected improvement in mechanical properties. Cohesive strength between copper fibers as a result of plastic deformation (by deformation, e.g. rolling), increased and decreased before and after sintering in relation to the loosely built structure (Table 1 ). The result of the tests is the arithmetic average of strength from at least three measurements, whose lowest and highest value under the fractional line is shown in the denominator.

Table 1. Mechanical properties of porous structure before and after pressing

\begin{tabular}{|l|c|c|}
\hline \multirow{2}{*}{$\begin{array}{c}\text { The structure } \\
\text { underwent pressing }\end{array}$} & \multicolumn{2}{|c|}{ Mechanical properties } \\
\cline { 2 - 3 } & $\mathrm{F}_{m}, \mathrm{~N}$ & $\mathrm{~A}, \%$ \\
\hline after sintering & $\frac{31.9}{27.5 \div 36.3}$ & 6.3 \\
\hline before sintering & $\frac{44.15}{37.8 \div 48.3}$ & 9.4 \\
\hline
\end{tabular}

The sintering process of single element components includes the initial stage of intermolecular interface surface growth, intermediate pore closure stage and final stage of coagulation and disappearance of isolated pores.

For example, changes occurring as sintering progresses in the structure of sintered copper can be seen in Figure 4. In the places of the greatest density, i.e. in the fiber joints where the cross-sections of the wire are the smallest and the greatest forces, the recrystallization (recovery) processes began. New crystalline grain systems were created, different from the original one. The photo shows a diffusion fiber connection at the grain boundary, which passes through the bridge. The effect of grain migration into one of the connecting elements is the result of the creation of a uniform material with randomly scattered pores on copper fibers.

The analysis of the proper selection of the sintering parameters of the structure was the result of measuring the width of the measured bridges of randomly (Table 2) chosen connections (n), fibrous structure components in $\mathrm{i}$ - volumes, which were approximated by a log-normal distribution.

Analysis of this function indicates that the distribution of connections can be approximated by a normal distribution with the parameters: mean: $14.294 \mu \mathrm{m}$, standard deviation (sd) 5.1577 (Figure 5).

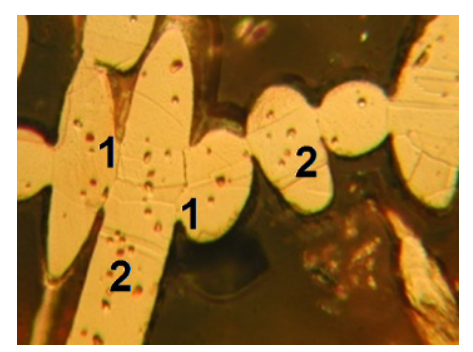

Figure 4. Diffuse fusion of fibers on the grain boundary (1) with pores (2)

Table 2. Parameters of statistical treatment of diameters of the length of bridges between fibers

\begin{tabular}{|c|l|c|c|c|c|}
\hline $\mathrm{V}_{\mathrm{i}}$ & \multicolumn{1}{|c|}{$\begin{array}{c}\text { The size of } \\
\text { the set }\end{array}$} & $\mathrm{n}$ & $\bar{x}$ & Dispersion & $\begin{array}{c}\text { Kolmogorov } \\
\text { criterion }\end{array}$ \\
\hline 1. & length of & 67 & 12.308 & 3.4070 & $1.257<1.304$ \\
\cline { 2 - 6 } 2. & bridges & 52 & 14.294 & 5.1577 & $1.131<1.304$ \\
\hline
\end{tabular}

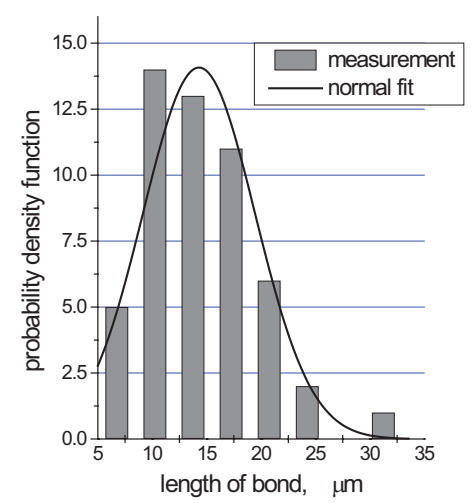

Figure 5. Quantitative distribution function of diffusion bridges between fibers 
The above assumption about the normal distribution of bridge diameters has been checked by Kolmogorov criterion, which arose from the distribution characterized by the maximum difference of experimental $\mathrm{F} \cdot(\mathrm{x})$ and theoretical $F(x)$ values of the distribution function of $n_{i}-$ values in the set:

$$
D_{n}=\sup _{-\infty<x<\infty}|F \cdot(x)-F(x)|=\max \left|D_{n}^{-}, D_{n}^{+}\right|,
$$

where:

$$
\begin{aligned}
& D_{n}^{+}=\max _{l<i<n}\left(\frac{i}{n}-F_{i}\right)-\text { upper limit; } \\
& D_{n}^{-}=\max _{l<i<n}\left(F_{i}-\frac{i-1}{n}\right)-\text { lower limit. }
\end{aligned}
$$

At deformation, the components in the fibrous structure increase stresses in a given volume of fibers, causing first the weakest fiber to be destroyed and then the entire structure. And only after reaching (stress) the maximum force of destruction, the n-number of fibers will be destroyed. If the structure is reinforced with a copper mesh, the destructive fiber volumes cause an increase in stress due to the rearrangement of stresses between the remaining fibers on the smaller surface and the length of the fiber, in particular the length of the bridges (fiber-mesh, mesh-base).

With the destruction of the fibers in the structure, it continues to work by rearranging the stresses (forces) between neighboring material components at the ineffective length of the fiber $\left(l_{\mathrm{kr}}=\right.$ we take the average length of the bridge between the fibers, or the average mesh bridges with copper substrate defined in Table 3 and Table 4, respectively).

This is the length at which the fiber can no longer regroup the stresses to the neighboring components of the composite under influence of stress tangents, which reflects the stress distribution of Weibull $\sigma$.

In addition, the force $(\mathrm{F})$ needed to disconnect the diffusion-adjacent components (i.e., the fibers) was estimated. The cohesion between the components of the porous structure subjected to pressing after sintering has been estimated at 60-78 N at $69 \mathrm{~N}$ (Chatys \& Orman, 2017).

Table 3. Model parameters

\begin{tabular}{|l|l|}
\hline Parameters & \multicolumn{1}{|c|}{ Dependencies } \\
\hline $\begin{array}{l}\text { Tangential } \\
\text { stress }\end{array}$ & $\tau=\frac{\sigma_{k r} \cdot D}{l_{k r}},(2)$ \\
& $\begin{array}{l}\text { where: } \\
\mathrm{D}-\text { fiber diameter, } l_{c}-\text { critical fiber length, } \\
\sigma-\text { fiber strength at critical fiber length }\end{array}$ \\
\hline $\begin{array}{l}\text { Maximum } \\
\text { stresses }\end{array}$ & $\begin{array}{l}\left.\sigma=\left(\alpha l_{k r}\right)^{(-1 / \beta \cdot t}\right)-j \beta \\
\text { where: } \\
\alpha, \beta, \mathrm{j}-\text { distribution parameters; } \mathrm{t}, \mathrm{S}, \mathrm{l}-\text { ave- } \\
\text { rage dimensionless time, strain and fiber } \\
\text { length. }\end{array}$ \\
\hline
\end{tabular}

\section{Effect of reinforcement in sintering of single- component materials}

Analogous phenomena are observed at the fiber-base interface (Figure 6). The reason for this is the reaction between copper oxide and diffusible hydrogen (swelling of the material as a result of the so-called "hydrogen disease") from the surface into the copper and the influence of sintering on the deformation of the structure (Figure 7).

The described phenomena develop the surface (open pores), creating open cavities (increasing the number of nucleation sites: Figure 8), which in the processes of heat intensification is of fundamental importance (Table 4).

Improving the quality of the copper structure connection with a mesh layer by $6-9 \%$ was an increase in the width of the bridge of randomly selected connections, components of the fibrous structure, whose obtained set was used to determine the distribution function (log-normal approximation) for diffusion bridges of the mesh with the substrate (Table 4).

Sintering of such a substrate (i.e. with a mesh, fibrous elements) creates additional contact surfaces that transport heat deeper into the surface of the substrate as a result of larger wire diameters (filaments) in the mesh than between the filaments. It should be mentioned that a significant (almost threefold) difference in the thickness of the wire mesh and fibers results in a greater average size of bridge connections from $14.3 \mu \mathrm{m}$ (Figure 5) to $38.4 \mu \mathrm{m}$ (Figure 9) for fibrous elements and mesh with the ground. And thus, reducing the porosity of the layer from approx. $83-85 \%$ in the area of the fibrous layer to approx. $60-63 \%$ at the heating surface (Orman, 2016) creating a favorable structure with elements with the features of a triangular shape (Chatys \& Orzechowski, 2004).

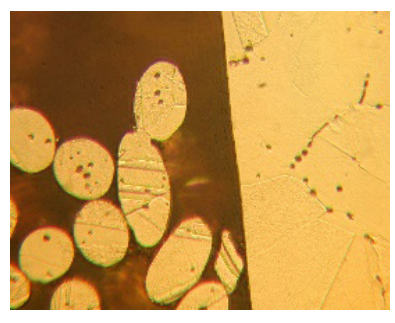

a)

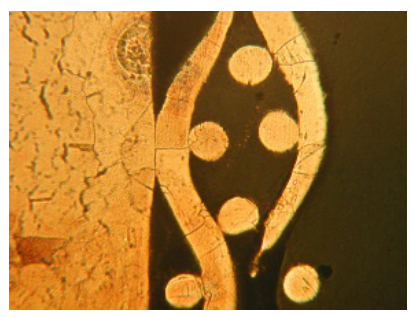

b)
Figure 6. The fragment of the fiber contact with the base (a) and the base with the mesh (b) in the copper structure

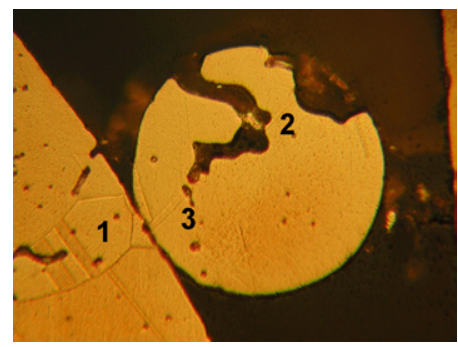

Figure 7. Effects of "hydrogen disease": open (2) and closed (3) pores on fibers and grain boundaries (1) 


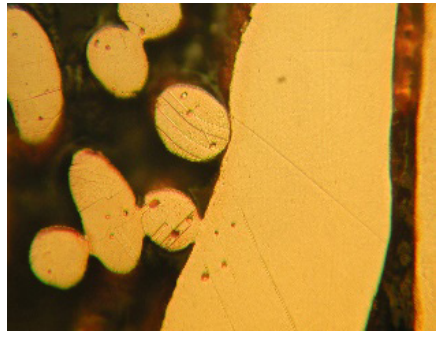

a)

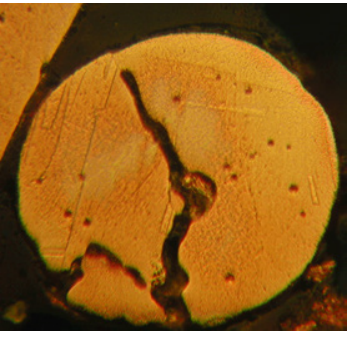

b)

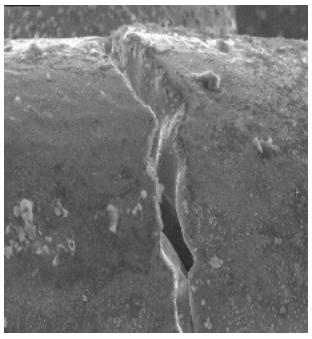

c)

Figure 8. The effect of "hydrogen disease": in structure (a) in the fiber (b) and the copper mesh (c)

Table 4. Parameters of statistical processing (Paramonov, 1992) of fiber pore diameters in the i-volume (1), and the diameters of the length of copper mesh bridges (2)

\begin{tabular}{|c|l|c|c|c|c|}
\hline $\mathrm{V}_{\mathrm{i}}$ & The size of the set & $\mathrm{n}$ & $\bar{x}$ & Dispersion & $\begin{array}{c}\text { Kolmogo- } \\
\text { rov crite- } \\
\text { rion }\end{array}$ \\
\cline { 1 - 4 } 1a. & Pore diameter & 31 & 3.7489 & 0.7891 & $\begin{array}{c}0.6961< \\
0.99\end{array}$ \\
\cline { 1 - 4 } 1b. & 27 & 3.9765 & 0.9649 & $\begin{array}{c}0.7490< \\
0.99\end{array}$ \\
\hline 2. & $\begin{array}{l}\text { Diameter of mesh } \\
\text { bridges with } \\
\text { copper substrate } \\
\text { (Figure 9) }\end{array}$ & 21 & 38.443 & 4.821 & $\begin{array}{c}1.156< \\
1.304\end{array}$ \\
\hline
\end{tabular}

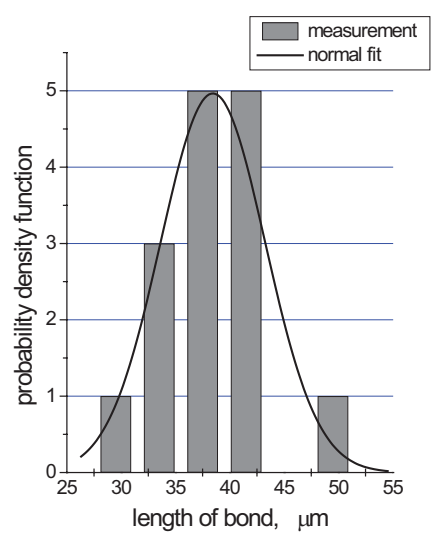

Figure 9. Quantitative distribution function of diffusion bridges between the copper surface and randomly spun fibrils (diameter of mesh bridges with copper substrate)

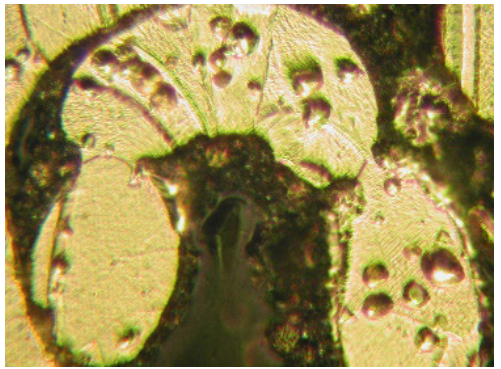

a)

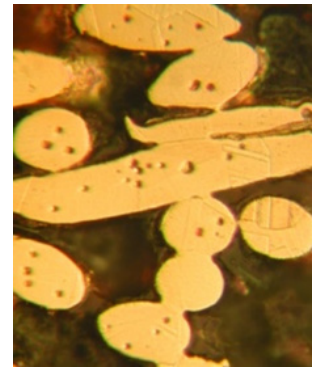

b)
Figure 10. The effect of "hydrogen disease" on copper fiber bridges $(a, b)$
A pore, as a component of the structure in which the protective atmosphere is stored (Figure 10) or water vapor is a source of stress. If the outlet for the excess vacancy was the convex surface of the particle, then according to the direction of the diffusion streams, the increase of the contact plane does not lead to the approximation of the particle centers (Orman, 2019) as it did at the interface between the molecules.

The share of adhesive strength is very different and in each case different, which causes that the quality of the joint may have different adhesive strengths due to diffusion bridges with open and closed pores (improving the skeletal structure in the obtained diffusion layers - Figure 10b).

The addition of adhesive strength in addition to the mesh was also achieved by introducing glass and carbon fibers respectively by 30 and $47 \%$ (Chatys \& Orman, 2017).

\section{Conclusions}

The considered fibrous microstructures can be part of efficient phase - change heat exchangers used in aviation systems, for example in their air conditioning units. The analysis of porous joint tests of randomly selected volumes confirmed the log-normal distribution for the width of the bridges, the fiber pores, and the width of the diffusion bridges of the mesh with the ground. The complexity of the obtained fibrous structures makes it possible to control and obtain the required open porosity (by selecting sintering parameters), and increases the adhesive strength (which is very different and in each case different). It depends to a large extent on the distribution of diffusion bridges (stresses) in the obtained structure, recrystallization processes or the presence of sources of vacant outlets via boundaries or edge dislocations (as a result of copper oxides with diffused hydrogen: the so-called "hydrogen disease" of copper). The quality of the connection of the porous structure reinforced with the copper mesh determines better cohesive properties between the components of the structure.

\section{References}

Bar-Cohen, A. A., \& Simon, T. W. (1986). Well superheat excursions in the boiling incipience of dielectric fluids. In A. Bar-Cohen (Ed.), Heat transfer in electronic equipment, ASME, HTD, 57, 83-94. 
Bohdal, T. (2017). Bubble boiling in flow of refrigerating media. Journal of Mechanical and Energy Engineering, 1, 41(1), 57-64.

Cieśliński, J. T. (1996). Study of nucleate boiling at the surfaces of the porous metal. Scientific Notebook Gdansk University of Technology, LXXVI(547).

Chatys, R., \& Wójcik, T. M. (2008). Polish Patent No. PL 202493 "Solar collector absorber coating".

Chatys, R., \& Koruba, Z. (2005). Gyroscope-based control and stabilization of Unmanned Aerial Mini-Vehicle (MINI-UAV). Aviation, IX(2), 10-16.

https://doi.org/10.3846/16487788.2005.9635898

Chatys, R., \& Orman, Ł. J. (2017). Technology and properties of layered composites as coatings for heat transfer enhancement. Mechanics of Composite Materials, 53(3), 351-360.

https://doi.org/10.1007/s11029-017-9666-8

Chatys, R., \& Orzechowski, T. (2004). Surface extension in layered structures with the use of metal meshes for heat-transfer enhancement. Mechanics of Composite Materials, 40(2), 159168. https://doi.org/10.1023/B:MOCM.0000025490.66094.86

Cheng, L., Xia, G., Li, Q., \& Thome, J. R. (2018). Fundamental issues, technology development, and challenges of boiling heat transfer, critical heat flux, and two-phase flow phenomena with nanofluids. Heat Transfer Engineering, 7632, 1-36. https://doi.org/10.1080/01457632.2018.1470285

Fang, X., Chen, Y., Zhang, H., Chen, W., Dong, A., \& Wang, R. (2016). Heat transfer and critical heat flux of nanofluid boiling: a comprehensive review. Renewable and Sustainable Energy Reviews, 62, 924-40.

https://doi.org/10.1016/j.rser.2016.05.047

Gapiński, D., \& Stefański, K. (2014). Control of designed target seeker, used in self-guided anti-aircraft missiles, by employing motors with a constant torque. Aviation, 18(1), 20-27. https://doi.org/10.3846/16487788.2014.865943

Good, R. J. (1975). Adhesion science and technology. Plenum Press.

Hussein, A. K. (2015). Applications of nanotechnology in renewable energies a comprehensive overview and understanding. Renewable and Sustainable Energy Reviews, 42, 460-476. https://doi.org/10.1016/j.rser.2014.10.027

Kamel, M. S., \& Lezsovits, F. (2018). Simulation of nanofluids laminar flow in a vertical channel. Pollack Period, 13(1), 147158. https://doi.org/10.1556/606.2018.13.2.15

Kandlikar, S. G., \& Grande, W. J. (2003). Evolution of microchannel flow pasages - termohydraulic performance and fabrication technology. Heat Transfer Engineering, 24(1), 3-17. https://doi.org/10.1080/01457630304040

Klett, W. (2000). Process for making carbon foam. US Patent 6033506.

Kuczyński, W. (2019). Experimental research on condensation of $\mathrm{R} 134 \mathrm{a}$ and R404A refrigerants in mini-channels during impulsive instabilities. Part I. International Journal of Heat and Mass Transfer, 128, 728-738. https://doi.org/10.1016/j.ijheatmasstransfer.2018.09.045

Laguerre, O., Amara, S. B., Alvarez, G., \& Flick, D. (2008). Transient heat transfer by free convection in a packed bed of spheres: comparison between two modeling approaches and experimental results. Applied Thermal Engineering, 28(1), 14-24. https://doi.org/10.1016/j.applthermaleng.2007.03.014

Leong, K. C., \& Jin, L. W. (2008). Study of highly conductive graphite foams in thermal management applications. Advanced Engineering Materials, 10(4), 338-345. https://doi.org/10.1002/adem.200700332
Li, H. Y., \& Leong, K. C. (2011). Experimental and numerical study of single and two-phase flow and heat transfer in aluminium foams. International Journal of Heat and Mass Transfer, 54, 4904-4912.

https://doi.org/10.1016/j.ijheatmasstransfer.2011.07.002

Liang, G., \& Mudawar, I. (2019). Review of pool boiling enhancement by surface modification. International Journal of Heat and Mass Transfer, 128, 892-933.

https://doi.org/10.1016/j.ijheatmasstransfer.2018.09.026

Mikielewicz, D., Andrzejczyk, R, Jakubowska, B., \& Mikielewicz, J. (2016) Analytical model with nonadiabatic effects for pressure drop and heat transfer during boiling and condensation flows in conventional channels and minichannels, Heat Transfer Engineering, 37(13-14), 1158-1171. https://doi.org/10.1080/01457632.2015.1112213

Orman, Ł. J. (2016). Enhancement of pool boiling heat transfer with pin-fin microstructures. Journal of Enhanced Heat Transfer, 23, 137-153. https://doi.org/10.1615/JEnhHeatTransf.2017019452

Orman, Ł. J. (2020). Aspects of complexity of metal-fibrous microstructure for the construction of high-performance heat exchangers: thermal properties. Aviation (in print, 2020).

Paramonov, Yu. M. (1992). Methods of mathematical statistics in problems on the estimation and maintenance of fatigue life of aircraft structures (in Russian). Publication RIIGA.

Piasecka, M., \& Poniewski, M. E. (2016). Heat transfer and pressure drop in minichanels with microstructured surface and various orientation. Encyclopaedias of Two - Phase Heat Transfer and Flow I. Fundamentals and Method, 4: Special Topics in Pool and Flow Boiling, Chapter V, 107-130. J. R. Thome (Ed.). Word Scientific Publishing Co.Pte. Ltd. https://doi.org/10.1142/9789814623216_0031

Poniewski, M. E. (2001). Nucleate boiling on developed microsurfaces (in Poland). Kielce University of Technology, Kielce.

Pranoto, I., \& Leong, K. C. (2014). An experimental study of flow boiling heat transfer from porous structures in a channel. Applied Thermal Engineering, 70(1), 100-114.

https://doi.org/10.1016/j.applthermaleng.2014.04.027

Reutskiy, S. Y. (2004). Treffz type method for time-dependent problems. Engineering Analysis with Boundary Elements, 28(1), 13-21. https://doi.org/10.1016/S0955-7997(03)00115-2

Sickfeld, J. (1983). Adhesion aspects of polymeric coating. K. L. Mittal (Ed.). Plenum Press.

Song, L. S., \& Chang, H. S. (2015). An experimental study of $\mathrm{CHF}$ enhancement of wire nets covered surface in R-134a flow boiling under high pressure and high mass flux conditions. International Journal of Heat and Mass Transfer, 90, 761-768. https://doi.org/10.1016/j.ijheatmasstransfer.2015.07.022

Thome, J. R. (1990). Enhanced boiling heat transfer. Hemisphere.

Vakula, V. L., \& Pritykin, L. M. (1984). Physical chemistry adhesion of polymers. Chemistry (in Russian).

Verdy, C., Montavon, G., \& Coddet, C. (1998, 25-29 May). On the benavior of thick and porous copper deposits under compressive stress. Proceding of $15^{\text {th }}$ International Thermal Spray Conference (pp. 647-652). Nice, France.

Voyutskii, S. S. (1963). Autohesion and adhesion of high polymers. Wiley.

Zhao, C. Y., Lu, W., \& Tassou, S. A. (2009). Flow boiling heat transfer in horizontal metal-foam tubes. ASME J. Heat Transfer, 131(12), 121002-1-121002-7.

https://doi.org/10.1115/1.3216036

Zimon, A. D. (1977). Adhesion coating and cover. Chemistry (in Russian). 